\title{
RESEARCH
}

Open Access

\section{Identification of bronchiolitis profiles in Italian children through the application of latent class analysis}

\author{
Giuliana Ferrante ${ }^{1 *}$, Carmela Fondacaro ${ }^{1}$, Giovanna Cilluffo ${ }^{2}$, Piera Dones ${ }^{3}$, Francesca Cardella ${ }^{4}$ and \\ Giovanni Corsello ${ }^{1}$
}

\begin{abstract}
Background: Bronchiolitis is the primary infection of the lower respiratory tract in children under 2 years of age. Although it is generally considered a single nosological entity, recent studies suggested remarkable clinical heterogeneity. To date, no studies have identified classes of children with bronchiolitis within the Italian population. This study aimed to identify discrete profiles of Italian children hospitalized with bronchiolitis using a clustering approach and to compare findings with those obtained in international cohorts.

Methods: This was a retrospective single-centre study conducted on children aged $\leq 2$ years hospitalised with bronchiolitis $(n=401)$ at the Department of Infectious Diseases and the University Department of General Pediatrics in "Giovanni Di Cristina" Pediatric Hospital of Palermo, Italy, between November 2012 and May 2019. Bronchiolitis profiles were determined by latent class analysis, classifying children based on clinical characteristics at admission and viral aetiology.

Results: Three profiles were identified. Class 1 (49\%) was composed of $45 \%$ male children; all children were aged $\leq 6$ months at hospitalization; 77\% were infected with RSV; 100\% had respiratory distress, $11 \%$ had apnea and none had cough. Class 2 (77\%) was mainly composed of male subjects (51\%); 19\% were aged $>6$ months at admission; $37 \%$ were infected with RSV; $12 \%$ had respiratory distress, 5\% had apnea and 90\% had cough. Class 3 (19\%) included the largest proportion of male subjects (94\%) and was mostly composed of children aged $>6$ months at the time of admission (68\%); $70 \%$ had cough, $12 \%$ showed respiratory distress and none presented with apnoea. Children in Class 1 were more frequently born near the epidemic season $(p=0.028)$; breastfeeding duration was significantly longer for children in Class 3 ( $p=0.004)$.

Conclusions: The study identified distinct clinical profiles of bronchiolitis by a clustering approach in a singlecentre study of children hospitalised for bronchiolitis in Italy. The three bronchiolitis profiles share some similarities with those identified in international studies using the same statistical approach. These findings may help to increase the understanding of the phenotypic variability that typically characterizes bronchiolitis, with relevant implications for future research.
\end{abstract}

Keywords: Bronchiolitis, Children, Latent class analysis, Respiratory syncytial virus

\footnotetext{
* Correspondence: giuliana.ferrante@unipa.it

'Department of Health Promotion Sciences Maternal and Infant Care, Internal Medicine and Medical Specialities, University of Palermo, Via del Vespro 129, 90127 Palermo, Italy

Full list of author information is available at the end of the article
}

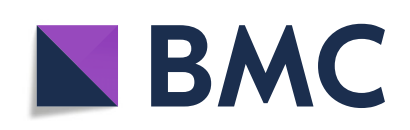

(- The Author(s). 2020 Open Access This article is licensed under a Creative Commons Attribution 4.0 International License, which permits use, sharing, adaptation, distribution and reproduction in any medium or format, as long as you give appropriate credit to the original author(s) and the source, provide a link to the Creative Commons licence, and indicate if changes were made. The images or other third party material in this article are included in the article's Creative Commons licence, unless indicated otherwise in a credit line to the material. If material is not included in the article's Creative Commons licence and your intended use is not permitted by statutory regulation or exceeds the permitted use, you will need to obtain permission directly from the copyright holder. To view a copy of this licence, visit http://creativecommons.org/licenses/by/4.0/. The Creative Commons Public Domain Dedication waiver (http://creativecommons.org/publicdomain/zero/1.0/) applies to the data made available in this article, unless otherwise stated in a credit line to the data. 


\section{Background}

Bronchiolitis is the primary infection of the lower respiratory tract in children under 2 years of age, imposing a huge clinical burden as one of the commonest causes of hospital admission in this age group [1-4]. Although it is generally considered a single nosological entity, the clinical presentation could be extremely variable and recent studies have suggested that this condition is characterized by remarkable heterogeneity $[5,6]$. Even hospitalized children may show various shortterm outcomes (eg. length of hospital stay, risk of recurrence) [7-9], as well as different mid- and long-term sequelae, such as the risk of developing recurrent wheezing and asthma $[10,11]$. Therefore, identifying different disease phenotypes might contribute to develop and implement proper preventive and therapeutic strategies. Most of the studies conducted so far have generally classified children with bronchiolitis on the basis of a limited number of characteristics (eg. type of virus, presence of wheezing, severity score). Of note, a multidimensional approach has proven to be more effective in clarifying the intrinsic heterogeneity of other respiratory disorders such as asthma and wheezing in childhood. In this context, clustering statistical methods are suitable for categorizing a heterogeneous population into subpopulations who share some aspects of a disease [12]. In particular, Latent Class Analysis (LCA) is a "hypothesis-free" approach, which assigns patients to classes based on their homogeneous characteristics, rather than them being arbitrarily assigned to classes by the researchers [13]. This method has been successfully used to detect subgroups of children with wheezing or asthma who share similar characteristics of the disease [14-17]. Using this statistical approach in multicenter cohorts of US (MARC-30 USA) and Finnish (MARC-30 Finland) children hospitalized with severe bronchiolitis, disease profiles were identified that differed based on the personal history of wheezing/eczema, wheezing during acute infection, severity levels and viral aetiology [18]. More recently, LCA has been applied in a study conducted on a large cohort of US children (MARC-35) hospitalized for bronchiolitis and followed up to the age of three, allowing the identification of three disease profiles significantly different with respect to inflammation and atopy markers, the nasopharyngeal microbiota, and the development of recurrent wheezing at 3 years of life [19].

No similar studies have been performed in the Italian children population so far. Therefore, the aim of the current study was to identify and describe discrete profiles of children hospitalized with bronchiolitis by means of LCA in a retrospective, single centre study conducted in Palermo, Italy, and to compare our findings with those obtained in international cohorts.

\section{Methods}

\section{Study design and data collection}

This is a retrospective observational study conducted on children aged $\leq 2$ years hospitalized for bronchiolitis at the Department of Infectious Diseases and the University Department of General Pediatrics in "Giovanni Di Cristina" Pediatric Hospital of Palermo, Italy, between November 2012 and May 2019. Patients were identified based on a bronchiolitis diagnosis (ICD-10 code J21.0 9) at discharge. Patients' medical files were reviewed to check that bronchiolitis diagnosis was in accordance with international guidelines [3] and data relevant to the study were analysed and reported anonymously, thus the ethical research committee approval was waived.

The following data were collected: gender, age, number of cohabitants in the home, number of siblings; mode of delivery, gestational age, birth weight, perinatal problems (need for resuscitation, $\mathrm{O}_{2}$ therapy, hospitalization, administration of surfactant, mechanical ventilation), prophylaxis with Palivizumab, breastfeeding history; underlying chronic diseases; clinical characteristics at admission: weight, respiratory rate, $\mathrm{SpO}_{2}$, body temperature, occurrence of respiratory, gastrointestinal and neurological symptoms and signs, feeding difficulties; chest radiological findings, type of virus identified in the nasal swab; treatment; number of days of hospitalization.

Viruses were detected in nasopharyngeal swabs by genome detection using reverse transcriptase polymerase chain reaction or by viral antigens detection using immunofluorescence or enzyme immunoassays. All samples were tested for the presence of RSV, RV, Enterovirus, Influenza virus $A$ and $B$, Parainfluenza virus 1-4, human Coronavirus OC43, 229E, NL-63 and HUK1, Adenovirus, and Human Metapneumovirus.

\section{Statistical analysis}

Data were presented as $\mathrm{n}$ (\%) or mean (SD). Differences of categorical variables were analysed using Chi-squared test. LCA was used to discover underlying response patterns, thus allowing the identification of respondent groups with similar characteristics. LCA was computed using the $\mathrm{R}$ poLCA package, which estimates the latent class model by maximizing, with respect to $p_{r}$ and $\pi_{j r k}$, the following log-likelihood function:

$$
\ln L=\sum_{i=1}^{N} \ln \sum_{r=1}^{R} p_{r} \prod_{j=1}^{J} \prod_{k=1}^{K_{j}} \pi_{j r k}^{Y_{i j k}}
$$

where J indicates polytomous categorical variables (manifest variables), each containing $K_{j}$ possible outcomes, for individuals $\mathrm{i}=1 \ldots \mathrm{N} ; Y_{i j k}$ denotes observed values of $\mathrm{J}$ manifest variables such that $Y_{i j k}=1$ if the respondent $i$ gives the $\mathrm{k}$-th response to the $\mathrm{j}$-th variable, and $Y_{i j k}=0$ otherwise; $\pi_{j r k}$ denotes class-conditional 
probability that an observation in class $r=1 \ldots . . R$ produces the $\mathrm{k}$-th outcome on the $\mathrm{j}$-th variable and $p_{r}$ indicates $\mathrm{R}$ mixing proportions. poLCA takes advantage of the iterative nature of the expectation-maximization algorithm to make it possible to estimate the latent class model even when some of the observations on the manifest variables are missing.

The method assumes that all associations between the included variables are entirely due to the existence of distinct subpopulations called latent classes. Within the latent classes all variables are assumed to be independent [20]. The responses to these items (i.e. manifest variables) were used to categorize respondents into groups with similar response profiles (i.e. latent classes). Variable selection for LCA was performed in order to find the set of variables with relevant clustering information and to discard those that were redundant and/or not informative. For performing variable selection, we used LCAvarsel [21] function with forward search strategy. The algorithm starts from the minimum subset of variables that allows a latent class analysis model to be identified, then the variables are added/removed in turn to/ from the set of clustering variables until no further change to the set of selected ones. The initial set of clustering variables is chosen by default using the strategy described in Dean and Raftery [22]. The final model included gender, age ( $<6$ months or $\geq 6$ months), RSV infection (yes or no), respiratory distress (yes or no), apnea (yes or no), and cough (yes or no). The Akaike Information Criterion (AIC) [23] was computed in order to select the best number of classes by comparing models with one to five classes.

AIC derived from LCAs suggested that a three-class model was favoured. Robustness of our results was tested by fitting LCA excluding children $\geq 12$ months old with findings substantially unchanged (Fig. S1). Analyses were performed using R 3.5.2 software. A $p$-value $<0.05$ was considered statistically significant.

\section{Results}

\section{Characteristics of study population}

A total of 401 children were enrolled. Table 1 reports demographic, perinatal and neonatal characteristics of the study population. Fifty-five children were preterm born. Three children were diagnosed with a chromosomic syndrome and ten had congenital heart diseases. One child had intestinal atresia, one had congenital hypothyroidism and another one had a diagnosis of epilepsy. Out of the 55 preterms enrolled in the study, two were affected by Down syndrome and three had congenital heart disease.

Table 2 reports demographic, clinical, microbiological and radiological findings at hospitalization. 59.1\% of the study sample was represented by male patients; $70.32 \%$
Table 1 Demographic, perinatal and neonatal characteristics of the study population

\begin{tabular}{ll}
\hline & $\boldsymbol{n}=\mathbf{4 0 1}$ \\
\hline Gestational age, weeks & $38.25(2.86)$ \\
Preterm birth (gestational age < 37 weeks) & $55(13.7)$ \\
Singleton delivery & $3.07(0.60)$ \\
Type of delivery & $390(97.25)$ \\
$\quad$ Elective caesarean section & \\
Emergency caesarean section & $113(30.38)$ \\
Vaginal & $43(11.56)$ \\
O $_{2}$ therapy at birth & $216(58.06)$ \\
Resuscitation & $33(8.23)$ \\
Surfactant at birth & $23(5.74)$ \\
Neonatal hospitalization & $4(1.00)$ \\
Mechanical ventilation & $47(11.72)$ \\
First-born & $11(2.74)$ \\
Number of siblings & $162(40.40)$ \\
Number of cohabitants & $0.91(1.09)$ \\
Birth within 3 months of the epidemic season start & $3.74(1.29)$ \\
Breastfeeding (exclusively) & $22(5.49)$ \\
Breastfeeding duration, months & $108(37.24)$ \\
Palivizumab prophylaxis & $0.61(1.71)$ \\
\hline
\end{tabular}

Data are presented as $\mathrm{n}(\%)$ or mean (SD)

were aged less than 6 months at the time of admission. The most frequently observed clinical findings were: cough (83.46\%), respiratory distress $(53.94 \%)$ and rhinorrea (34.61\%). All children underwent nasal swabs for microbiological diagnosis. In $53.61 \%$ viruses could not be identified; in $44.13 \%$ a single virus was detected and in $2.24 \%$ a double viral infection was found. The most common viruses detected in nasal swabs were: RSV (35.91\%), Parainfluenza virus $(6.23 \%)$ and Influenza virus (2\%). Chest X-ray was performed in $56.86 \%$ of patients and pneumonia was the most frequently observed finding (30.67\%).

\section{Latent class analysis}

Five models were estimated from Model 0 (with only one class) to Model 4 (with five classes). The AIC derived from LCA suggested that a three-class model was favoured by the lowest AIC (Fig. 1).

Figure 2 illustrates the three classes identified by means of LCA.

Class $1(n=14,3.49 \%)$ was composed of $45 \%$ male children; all children in this class were aged $\leq 6$ months at hospitalization; most of them were infected with RSV (77\%); 100\% had respiratory distress, $11 \%$ had apnea and none had cough.

Class $2(n=309,77 \%)$ was predominantly composed of male children (51\%); $19 \%$ were aged $>6$ months at 
Table 2 Demographic, clinical, microbiological and radiological findings at hospitalization

\begin{tabular}{|c|c|}
\hline Gender, male & $237(59.1)$ \\
\hline Age, months & $4.70(4.93)$ \\
\hline Weight, Kg & $6.41(2.49)$ \\
\hline \multicolumn{2}{|l|}{ Clinical findings } \\
\hline RR (breaths/min) & $50.28(11.19)$ \\
\hline $\mathrm{SpO}_{2}, \%$ & $96.04(3.35)$ \\
\hline Fever & $3(0.76)$ \\
\hline Rhinorrea & $136(34.61)$ \\
\hline Cough & $328(83.46)$ \\
\hline Wheezing & $3(0.76)$ \\
\hline Apnoea & $16(4.07)$ \\
\hline Respiratory distress & $212(53.94)$ \\
\hline Cyanosis & $15(3.82)$ \\
\hline Feeding difficulties & $20(5.09)$ \\
\hline Hypotonia & $1(0.25)$ \\
\hline Seizures & $1(0.25)$ \\
\hline \multicolumn{2}{|l|}{ Microbiological findings } \\
\hline None & $215(53.61)$ \\
\hline One virus & $177(44.13)$ \\
\hline Co-infections ( $\geq 2$ viruses) & $9(2.24)$ \\
\hline VRS & $144(35.91)$ \\
\hline Parainfluenza & $25(6.23)$ \\
\hline Influenza & $8(2.00)$ \\
\hline Rhinovirus & $2(0.50)$ \\
\hline Adenovirus & $3(0.75)$ \\
\hline Coronavirus & $2(0.50)$ \\
\hline Enterovirus & $1(0.25)$ \\
\hline Chest $X$-ray findings & $228(56.86)$ \\
\hline Bronchitis & 195 (23.69) \\
\hline Pneumonia & $123(30.67)$ \\
\hline Atelectasis & $1(0.25)$ \\
\hline
\end{tabular}

Data are presented as $\mathrm{n}(\%)$ or mean (SD)

admission; 37\% were infected with RSV; $12 \%$ had respiratory distress, $5 \%$ had apnea and $90 \%$ had cough.

Class $3(n=78,19 \%)$ was characterized by the highest proportion of male children (94\%); $68 \%$ were aged $>6$ months at hospitalization; $27 \%$ were infected with RSV; $12 \%$ had respiratory distress, none had apnea and $70 \%$ had cough.

Table 3 compares demographic, perinatal and neonatal characteristics among the three latent classes. Children in Class 1 were more frequently born near the epidemic season $(p=0.028)$; breastfeeding duration was significantly longer for children in Class $3(p=0.004)$. Children in Class 2 were more frequently treated with systemic corticosteroids $(p<0.001)$, and low-flow oxygen therapy

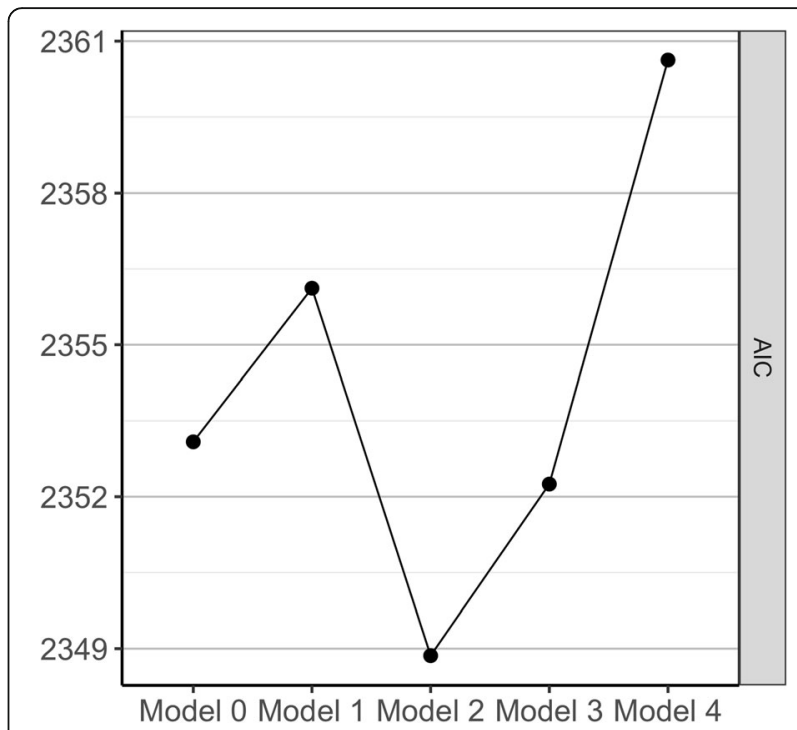

Fig. 1 AIC of different latent class models. The AIC derived from LCA suggested that a three-class model was favoured by the lowest AIC

$(p=0.042)$. Children in Class 3 more frequently were administered with systemic antibiotics $(p=0.013)$.

\section{Discussion}

The current study identified distinct clinical profiles of children hospitalised for bronchiolitis through the application of a hypothesis-free statistical clustering approach, such as LCA, which allowed us to describe three discrete phenotypes of patients based on gender, age, clinical characteristics at admission.

Clustering statistical methods are useful for identifying profiles that summarize shared aspects of disease within different groups of patients. LCA has been previously used to identify three to four homogeneous subgroups of patients starting from a large series of observed characteristics in multicenter cohorts of hospitalized children with severe bronchiolitis [18]. More recently, the same approach has been applied in a study conducted on a large population of US children hospitalized for bronchiolitis and followed up to the age of 3 years, finding three distinct profiles of children that showed significant differences with respect to markers of inflammation and atopy, nasopharyngeal microbiota, and respiratory outcomes by 3 years of age [19]. To our knowledge, no previous studies have identified classes of children with bronchiolitis within the Italian population. Noteworthy, the bronchiolitis profiles identified in the current study by means of LCA share some similarities with those identified in the aforementioned studies using the same statistical approach.

We identified a group of children (Class 1) predominately composed of female subjects and characterized by early onset ( $<6$ months of age) of symptoms. In this 

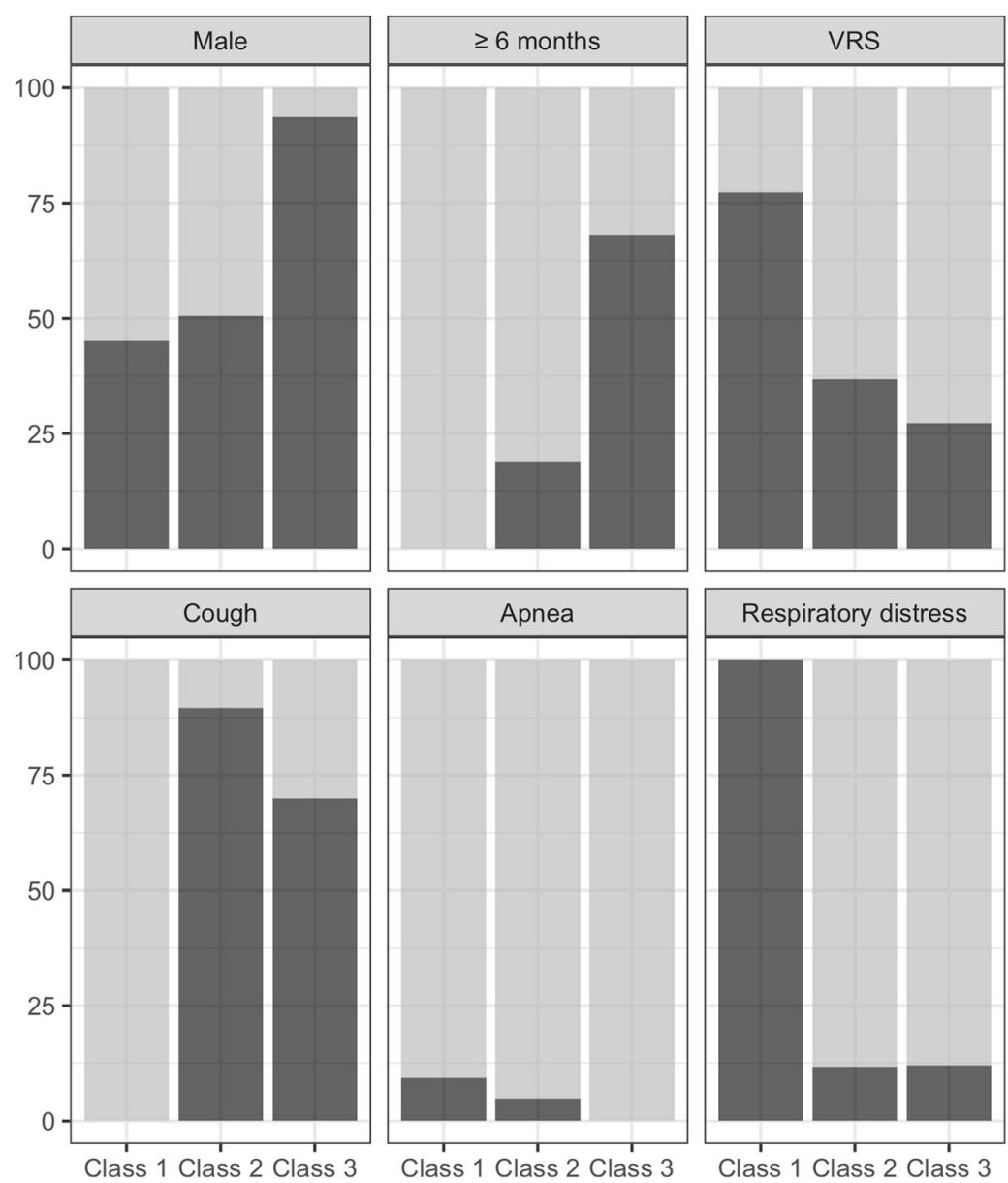

Fig. 2 Response probabilities among the three latent classes. The figure illustrates the three classes identified by means of LCA

group, bronchiolitis was mainly caused by RSV (77\%); all patients had respiratory distress, and apnoea episodes were present in $11 \%$. These children share similarities with Profile $C$ children identified in the two US cohorts (MARC-30 USA and MARC-35), in which patients showed the lowest age at admission, had the most severe clinical presentation and were mostly infected by RSV (> 80\%). Conversely, in the Finnish cohort (MARC-30 Finland), children with a more serious clinical presentation (Profile A) were mostly aged $\geq 12$ months and had an RV infection in 54\%. Interestingly, Profile $C$ children in the MARC-35 cohort showed an augmented risk of recurrent wheezing by age 3 years. This result confirms that the severity of bronchiolitis may influence mid-term respiratory outcomes, increasing the risk of recurrent wheezing and asthma later in life [24-26].

The largest group of children identified in the current study (Class 2) was mainly composed of male subjects; $19 \%$ were aged $>6$ months at the time of hospitalization and $37 \%$ were infected by RSV. The majority of children (90\%) had cough at presentation; $12 \%$ showed respiratory distress and $5 \%$ presented with apnoea. This class, characterized by an intermediate level of severity, shared similarities with Profile B children in the MARC-35 cohort and with Profile BC in the MARC-30 Finland cohort, both characterized by a prevalence of male subjects, which however showed a younger age at the time of hospitalization and were predominantly infected by RSV. On the other hand, no similarities could be detected with the bronchiolitis profiles identified in the MARC-30 USA cohort, probably due to the greater number of patients $(n=2207)$ which justifies an even more marked phenotypic heterogeneity in this population.

Class 3 included the largest proportion of male subjects (94\%) and was mostly composed of children aged > 6 months at the time of admission (68\%). $70 \%$ of children had cough, $12 \%$ showed respiratory distress and none presented with apnoea. Similarly to Profiles D identified in MARC-30 USA and MARC-30 Finland cohorts, this was the least severely ill group, and it differed from other classes by the lowest proportion of children with RSV infection (27\%), which was in agreement with Profile A in the MARC-35 cohort. Of note, also these profiles were mainly composed of male subjects and, 
Table 3 Demographic, perinatal and neonatal characteristics of the study population by LCs

\begin{tabular}{|c|c|c|c|c|}
\hline & Class 1 & Class 2 & Class 3 & $P$-value \\
\hline & $n=14$ & $n=309$ & $n=78$ & \\
\hline Age at hospitalization ( $\geq 6$ months) & $0(0.00)$ & $34(11.26)$ & $78(100.00)$ & $<0.001$ \\
\hline Gestational age, weeks & $38.79(1.97)$ & $38.23(3.02)$ & $38.23(2.27)$ & 0.775 \\
\hline Birth weight, $\mathrm{Kg}$ & $3.05(0.48)$ & $3.10(0.60)$ & $2.97(0.60)$ & 0.339 \\
\hline Singleton delivery & $14(100.00)$ & $301(97.41)$ & $75(96.15)$ & 0.678 \\
\hline Type of delivery & & & & 0.534 \\
\hline Elective caesarean section & $4(28.57)$ & $91(31.71)$ & $18(25.35)$ & \\
\hline Emergency caesarean section & $2(14.29)$ & $29(10.10)$ & $12(16.90)$ & \\
\hline Vaginal & $8(57.14)$ & $167(58.19)$ & $41(57.75)$ & \\
\hline $\mathrm{O}_{2}$ therapy at birth & $2(14.29)$ & $22(7.12)$ & $9(11.54)$ & 0.314 \\
\hline Resuscitation & $1(7.14)$ & $15(4.85)$ & $7(8.97)$ & 0.366 \\
\hline Surfactant at birth & $0(0.00)$ & $3(0.97)$ & $1(1.28)$ & 0.902 \\
\hline Neonatal hospitalization & $2(14.29)$ & $38(12.30)$ & $7(8.97)$ & 0.685 \\
\hline Mechanical ventilation & $1(7.14)$ & $7(2.27)$ & $3(3.85)$ & 0.441 \\
\hline First-born & $4(28.57)$ & $121(39.16)$ & $37(47.44)$ & 0.271 \\
\hline Number of siblings & $0.93(0.83)$ & $0.96(1.13)$ & $0.73(0.91)$ & 0.256 \\
\hline Number of cohabitants & $3.64(1.45)$ & $3.79(1.26)$ & $3.55(1.35)$ & 0.322 \\
\hline Birth within 3 months of the epidemic season start & $3(21.43)$ & $15(4.85)$ & $4(5.13)$ & 0.028 \\
\hline Breastfeeding (exclusively) & $1(9.09)$ & $79(35.75)$ & $28(48.28)$ & 0.113 \\
\hline Breastfeeding duration, months & $0.21(0.80)$ & $0.48(1.63)$ & $1.18(2.04)$ & 0.004 \\
\hline Palivizumab prophylaxis & $0(0.00)$ & $2(0.64)$ & $0(0.00)$ & - \\
\hline Hypertonic saline & $1(7.14)$ & $5(1.62)$ & $0(0.00)$ & 0.120 \\
\hline Inhaled bronchodilators & $6(42.86)$ & $157(50.81)$ & $46(58.97)$ & 0.339 \\
\hline Inhaled corticosteroids & $9(64.29)$ & $233(75.40)$ & $66(84.62)$ & 0.120 \\
\hline Systemic corticosteroids & $12(85.71)$ & $282(91.26)$ & $55(70.51)$ & $<0.001$ \\
\hline Systemic antibiotics & $7(50.00)$ & $203(65.70)$ & $63(80.77)$ & 0.013 \\
\hline Low-flow oxygen therapy & $6(42.86)$ & $144(46.60)$ & $24(30.77)$ & 0.042 \\
\hline Length of hospital stay & $9.21(7.93)$ & $7.75(18.42)$ & $5.17(3.10)$ & 0.415 \\
\hline Intensive care admission & $2(14.29)$ & $38(12.30)$ & $7(8.97)$ & 0.685 \\
\hline
\end{tabular}

Data are presented as $\mathrm{n}(\%)$ or mean (SD)

with the exception of the MARC-30 USA cohort, they were characterized by a higher proportion of children aged $>6$ months.

With regard to the statistically different characteristics for the three classes identified in the current study, we found that children in Class 1 were more frequently born near the epidemic season. This is considered a risk factor both for the development of lower respiratory tract infections as well as for hospitalization in subjects with RSV infection, who likely develop more frequently severe symptoms if born during the first half of the epidemic season [27]. Together with the low age at the time of hospitalization $(<6$ months) and the higher prevalence of infections by RSV, this may have contributed to the greater severity of clinical presentation observed in children in Class 1 compared to the other two classes. Indeed, evidence suggests that the RSV aetiology is associated with greater severity of the clinical presentation [28-30] and that a lower age at admission is associated with greater clinical severity of the RSV infection [28, 31].

As a piece of further evidence derived by the comparison of the three classes identified in the current study, duration of exclusive breastfeeding was significantly longer in children in Class 3, which was characterized by the least clinical severity of the disease. Notably, the differences among LCA classes in breastfeeding duration are due to the highest percentage in Class 3 of children who were exclusively breastfed. Indeed, when children who were not exclusively breastfed are excluded similar duration of breastfeeding are found. Thus, duration of breastfeeding can be considered as a proxy of exclusive breastfeeding. Even though the length of exclusive 
breastfeeding observed in this study was on average lower than 6 months or even 4 months, our finding provides further evidence for a protective role of breastfeeding against the severity of bronchiolitis, probably due to immunomodulatory factors in human milk against the RSV, as suggested by previous studies [32, 33].

The application of a statistical methodology such as LCA allowed us to detect bronchiolitis profiles different in gender, age at the onset of symptoms, severity of the clinical picture. These profiles were obtained directly from the data collected within a heterogeneous sample of children rather than being arbitrarily assigned. The resulting classes show a certain degree of flexibility: each individual can be assigned to different classes with different probabilities and this classification reflects clinical reality more closely, emphasizing the effectiveness of a multidimensional approach in capturing the clinical heterogeneity of the disease. A possible drawback is given by the need to establish a priori the set of variables, which requires a certain degree of subjectivity in data analysis. A further limitation of our study is related to the identification of disease profiles in a cohort of hospitalized children, which are actually a small proportion of all children with bronchiolitis. For a better characterization of the disease, it could be useful to apply the same statistical approach also to children with a milder level of disease, not requiring hospitalization, as they could show different socio-demographic characteristics and risk factors, as well as different clinical characteristics, compared to patients with most severe cases. However, our study allowed us to highlight that even within the group of children with bronchiolitis who require hospitalization there is a certain level of heterogeneity that could influence the diagnostic and therapeutic approach. Furthermore, the choice to study this cohort of children is significant, given that bronchiolitis is the most frequent cause of hospitalization in infants [34] and that patients with more severe disease have a higher risk of developing respiratory sequelae later in life. Lastly, it should be acknowledged as a limitation that viruses could not be identified in more than $50 \%$ of the enrolled patients, thus our results should be interpreted with caution with respect to viral aetiology. Indeed, our virus detection rate was poor, likely due to the different diagnostic tests used (immunofluorescence/enzyme immunoassays vs. PCR) as well as to technical problems in collecting and storing biological samples. Nonetheless, our detection rate is quite similar to those reported in other epidemiologic studies in Italy $[35,36]$.

\section{Conclusions}

Describing profiles of a heterogeneous disease such as bronchiolitis could be useful in providing the appropriate clinical approach and in identifying the best available therapeutic choice. The current findings may help to increase the understanding of the phenotypic variability that typically characterizes bronchiolitis, although they need validation in further studies. Namely, prospective longitudinal studies are needed to define bronchiolitis phenotypes and endotypes through an integrated clinical, epidemiological and molecular approach in order to develop personalized clinical management and clarify the physiopathologic basis of mid- and long-term respiratory outcomes [6].

\section{Supplementary information}

Supplementary information accompanies this paper at https://doi.org/10. 1186/s13052-020-00914-4.

Additional file 1: Figure S1. Response probabilities among the three

latent classes excluding children aged $\geq 12$ months.

Abbreviations

AIC: Akaike Information Criterion; LCA: Latent Class Analysis; RSV: Respiratory syncytial virus; RV: Rhinovirus

Acknowledgements

We are grateful to Silvia Cannova, MD, for her contribution in data collection.

\section{Authors' contributions}

GF designed the study. CF, FC and PD contributed to the data collection. GC conducted the statistical analyses. GC and GF wrote the initial draft and had final responsibility for the decision to submit for publication. Giovanni Corsello performed a critical revision of the manuscript and offered precious technical advice on how the study might be improved. All authors provided substantial contributions to the conception or design of the work, or the acquisition, analysis, or interpretation of data for the paper, revised the manuscript for important intellectual content, approved the final version, and agreed to be accountable for all aspects of the work.

\section{Funding}

There is no founding source.

\section{Availability of data and materials}

The datasets used and/or analysed during the current study are available from the corresponding author on reasonable request.

Ethics approval and consent to participate

This study was performed in accordance with the Declaration of Helsinki and Good Clinical Practice guidelines.

\section{Consent for publication}

Not applicable.

\section{Competing interests}

The authors declare that they have non competing interests.

\section{Author details}

${ }^{1}$ Department of Health Promotion Sciences Maternal and Infant Care, Internal Medicine and Medical Specialities, University of Palermo, Via del Vespro 129, 90127 Palermo, Italy. ${ }^{2}$ National Research Council of Italy, Institute for Biomedical Research and Innovation, Via Ugo La Malfa 153, 90146 Palermo, Italy. ${ }^{3}$ Pediatric Infectious Diseases Unit, ARNAS Civico Di Cristina, Via Benedettini 1, 90134 Palermo, Italy. ${ }^{4}$ Department of Pediatrics, ARNAS Civico Di Cristina, Via Benedettini 1, 90134 Palermo, Italy. 
Received: 18 May 2020 Accepted: 30 September 2020

Published online: 07 October 2020

\section{References}

1. Baraldi E, Lanari M, Manzoni P, Rossi GA, Vandini S, Rimini A, et al. Intersociety consensus document on treatment and prevention of bronchiolitis in newborns and infants. Ital J Pediatr. 2014:40(1):65.

2. Florin TA, Plint AC, Zorc JJ. Viral bronchiolitis. Lancet. 2017;389(10065):211-24.

3. Ralston SL, Lieberthal AS, Meissner HC, Alverson BK, Baley JE, Gadomski AM, et al. Clinical practice guideline: the diagnosis, management, and prevention of bronchiolitis. Pediatrics. 2014;134(5):e1474-502.

4. Ghazaly M, Nadel S. Overview of prevention and management of acute bronchiolitis due to respiratory syncytial virus. Expert Rev Anti-Infect Ther. 2018;16(12):913-28.

5. Vicencio AG. Susceptibility to bronchiolitis in infants. Curr Opin Pediatr. 2010;22(3):302-6.

6. Hasegawa K, Dumas O, Hartert TV, Camargo CA Jr. Advancing our understanding of infant bronchiolitis through phenotyping and endotyping: clinical and molecular approaches. Expert Rev Respir Med. 2016;10(8):891-9.

7. Carroll KN, Gebretsadik T, Griffin MR, Wu P, Dupont WD, Mitchel EF, et al. Increasing burden and risk factors for bronchiolitis-related medical visits in infants enrolled in a state health care insurance plan. Pediatrics. 2008;122(1): 58-64.

8. Mansbach JM, Piedra PA, Teach SJ, Sullivan AF, Forgey T, Clark S, et al. Prospective multicenter study of viral etiology and hospital length of stay in children with severe bronchiolitis. Arch Pediatr Adolesc Med. 2012;166(8): 700-6.

9. Jartti T, Aakula M, Mansbach JM, Piedra PA, Bergroth E, Koponen P, et al. Hospital length-of-stay is associated with rhinovirus etiology of bronchiolitis. Pediatr Infect Dis J. 2014;33(8):829-34.

10. Feldman AS, He Y, Moore ML, Hershenson MB, Hartert TV. Toward primary prevention of asthma. Reviewing the evidence for early-life respiratory vira infections as modifiable risk factors to prevent childhood asthma. Am J Respir Crit Care Med. 2015;191(1):34-44.

11. Rossi GA, Colin AA. Infantile respiratory syncytial virus and human rhinovirus infections: respective role in inception and persistence of wheezing. Eur Respir J. 2015:45(3):774-89.

12. Nosetti L, Paglietti MG, Brunetti L, Masini L, La Grutta S, Cilluffo G, Ferrante G, Zaffanello M, Verrillo E, Pavone M, Niespolo AC, Broggi G, Cutrera R. IPRS (SIMRI)Task Force on Sleep Disordered Breathing (SDB-TF). Application of latent class analysis in assessing the awareness, attitude, practice and satisfaction of paediatricians on sleep disorder management in children in Italy. PLoS One. 2020;15(2):e0228377. https://doi.org/10.1371/journal.pone. 0228377. PMID: 32012194; PMCID: PMC6996829.

13. Collins LM, Lanza ST. Latent class and latent transition analysis: with applications in the social, behavioral, and health sciences. Wiley; 2010.

14. Siroux V, Garcia-Aymerich J. The investigation of asthma phenotypes. Curr Opin Allergy Clin Immunol. 2011;11(5):393-9.

15. Depner M, Fuchs O, Genuneit J, Karvonen AM, Hyvärinen A, Kaulek V, et al. Clinical and epidemiologic phenotypes of childhood asthma. Am J Respir Crit Care Med. 2014;189(2):129-38.

16. Brew BK, Chiesa F, Lundholm C, Örtqvist A, Almqvist C. A modern approach to identifying and characterizing child asthma and wheeze phenotypes based on clinical data. PLoS One. 2019:14(12):e0227091.

17. Henderson J, Granell R, Heron J, Sherriff A, Simpson A, Woodcock A, et al. Associations of wheezing phenotypes in the first 6 years of life with atopy, lung function and airway responsiveness in mid-childhood. Thorax. 2008; 63(11):974-80.

18. Dumas O, Mansbach JM, Jartti T, Hasegawa K, Sullivan AF, Piedra PA, et al. A clustering approach to identify severe bronchiolitis profiles in children. Thorax. 2016:71(8):712-8.

19. Dumas O, Hasegawa K, Mansbach JM, Sullivan AF, Piedra PA, Camargo CA Jr. Severe bronchiolitis profiles and risk of recurrent wheeze by age 3 years. J Allergy Clin Immunol. 2019;143(4):1371-9.

20. McLachlan GJ, Lee SX, Rathnayake SI. Finite mixture models. Annu Rev Stat Its Appl. 2019;6:355-78.

21. Fop M, Murphy T. LCAvarsel: variable selection for latent class analysis. $R$ Package Version., vol. 1; 2017.

22. Dean N, Raftery AE. Latent class analysis variable selection. Ann Inst Stat Math. 2010;62(1):11.
23. Anderson D, Burnham K, White G. Comparison of Akaike information criterion and consistent Akaike information criterion for model selection and statistical inference from capture-recapture studies. J Appl Stat. 1998; 25(2):263-82.

24. Bacharier LB, Cohen R, Schweiger T, Yin-DeClue H, Christie C, Zheng J, et al. Determinants of asthma after severe respiratory syncytial virus bronchiolitis. J Allergy Clin Immunol. 2012;130(1):91-100.

25. Burbank AJ, Szefler SJ. Current and future management of the young child with early onset wheezing. Curr Opin Allergy Clin Immunol. 2017;17(2):146

26. Carroll KN, Wu P, Gebretsadik T, Griffin MR, Dupont WD, Mitchel EF, et al. The severity-dependent relationship of infant bronchiolitis on the risk and morbidity of early childhood asthma. J Allergy Clin Immunol. 2009;123(5): 1055-61.

27. Simoes EA. Environmental and demographic risk factors for respiratory syncytial virus lower respiratory tract disease. J Pediatr. 2003;143(5):118-26.

28. Papoff P, Moretti C, Cangiano G, Bonci E, Roggini M, Pierangeli A, et al. Incidence and predisposing factors for severe disease in previously healthy term infants experiencing their first episode of bronchiolitis. Acta Paediatr. 2011;100(7):e17-23.

29. Hervás D, Reina J, Yañez A, Del Valle J, Figuerola J, Hervás J. Epidemiology of hospitalization for acute bronchiolitis in children: differences between RSV and non-RSV bronchiolitis. Eur J Clin Microbiol Infect Dis. 2012:31(8): 1975-81.

30. Midulla F, Nenna R, Scagnolari C, Petrarca L, Frassanito A, Viscido A, et al. How respiratory syncytial virus genotypes influence the clinical course in infants hospitalized for bronchiolitis. J Infect Dis. 2019;219(4):526-34.

31. Alvarez AE, Marson FA, Bertuzzo CS, Arns CW, Ribeiro JD. Epidemiological and genetic characteristics associated with the severity of acute viral bronchiolitis by respiratory syncytial virus. J Pediatr Versão Em Port. 2013; 89(6):531-43.

32. Dixon D-L. The role of human milk immunomodulators in protecting against viral bronchiolitis and development of chronic wheezing illness. Children. 2015;2(3):289-304.

33. Dixon D-L, Griggs KM, Forsyth KD, Bersten AD. Lower interleukin-8 levels in airway aspirates from breastfed infants with acute bronchiolitis. Pediatr Allergy Immunol. 2010;21(4p2):e691-6.

34. Fujiogi M, Goto T, Yasunaga H, Fujishiro J, Mansbach JM, Camargo CA, et al. Trends in bronchiolitis hospitalizations in the United States: 2000-2016. Pediatrics. 2019;144(6):e20192614.

35. Cangiano G, Nenna R, Frassanito A, Evangelisti M, Nicolai A, Scagnolari C, et al. Bronchiolitis: analysis of 10 consecutive epidemic seasons. Pediatr Pulmonol. 2016;51(12):1330-5.

36. Nenna R, Frassanito A, Petrarca L, Di Mattia G, Midulla F. Age limit in bronchiolitis diagnosis: 6 or 12 months? Front Pediatr. 2020:8:144.

\section{Publisher's Note}

Springer Nature remains neutral with regard to jurisdictional claims in published maps and institutional affiliations.
Ready to submit your research? Choose BMC and benefit from:

- fast, convenient online submission

- thorough peer review by experienced researchers in your field

- rapid publication on acceptance

- support for research data, including large and complex data types

- gold Open Access which fosters wider collaboration and increased citations

- maximum visibility for your research: over $100 \mathrm{M}$ website views per year

At $\mathrm{BMC}$, research is always in progress.

Learn more biomedcentral.com/submission 